\title{
Moon, Mars and Mundus: primary school children discover the nature and science of planet Earth from experimentation and extra-terrestrial perspectives
}

\author{
M.G. Kleinhans ${ }^{1,5, *}$, A.J. Verkade ${ }^{2}$, T. van Wessel ${ }^{5,6}$, M.A.S. Bastings ${ }^{6}$, W.A. Marra ${ }^{1}$, T. van Gog ${ }^{3}$, \\ W. van Westrenen ${ }^{4} \&$ M. Reichwein ${ }^{5}$
}

1 Universiteit Utrecht, Faculty of Geosciences, P0 Box 80115, NL-3508 TC Utrecht, the Netherlands

2 De Praktijk, Science Communication and Education, 0ostenburgermiddenstraat 210, 1018 LL Amsterdam, the Netherlands

3 Erasmus University Rotterdam, Institute of Psychology, P0 Box 1738, 3000 DR Rotterdam, the Netherlands

4 VU University Amsterdam, Faculty of Earth and Life Sciences, De Boelelaan 1085, 1081 HV Amsterdam, the Netherlands

5 Wetenschapsknooppunt Universiteit Utrecht (Science Education Hub and University Museum), Lange Nieuwstraat 106, 3512 PN Utrecht, the Netherlands

6 Utrecht University Centre for Teaching and Learning, Faculty of Social and Behavioural Sciences, P0 Box 80140, 3508 TC Utrecht, the Netherlands

* Corresponding author. Email: m.g.kleinhans@uu.nl

Manuscript received: 05 July 2014, accepted: 09 January 2015

\section{Abstract}

Like earth and planetary scientists, most children are curious about the world, the solar system and the rest of the universe. However, for various reasons primary schools emphasise language and calculus rather than natural sciences. When science is taught, examination systems often favour knowledge of the 'right' answer over the process of investigation and logical reasoning towards that answer. In order to continue to spark children's curiosity and their motivation to learn and discover, science education hubs at universities and science museums could collaborate more with schools and teachers, and are beginning to do so. The objective of this position paper is to report on recent experiences in earth and planetary science education for pupils in primary and secondary education, to provide examples and inspiration for scientists. We report three examples of initiation and consolidation of science education in primary schools in the Netherlands: (1) a focus on asking questions and seeking information to reason towards the answer, initiated with a classroom game, Expedition Mundus, (2) bringing pupils and teachers together outside their school in the science museum to gain confidence and self-efficacy, and (3) having children ask their own questions and do their own research guided by the empirical cycle, for example on experimentation on sandbox scale models of channels and crater lake deltas as found on Mars. The focus on other planets, fictitious and real, stimulates pupils to ask questions about planet Earth. Finally, we argue that involvement of more scientists in science education would not only benefit primary and secondary schools and future students but also university education and science communication with society.

Keywords: Earth, Moon, Mars, Mundus, science education

\section{Introduction}

\section{Problem definition and context}

Many children are fascinated by the workings of planet Earth and by other planets in the solar system (Fig. 1), and some such children develop into earth scientists and planetologists. However, earth science, and how it is done, receives very little attention in primary schools despite its importance for societies, which is obvious to most scientists. There are a few cases where a partnership between universities and neighbouring primary schools has led to strong improvement in science teaching, for instance in a planetary science programme developed by a scientist and a teacher based on planetary imagery of the Voyager missions (Herwitz \& Guerra, 1996). In this paper we discuss the context of this problem and how earth and planetary 


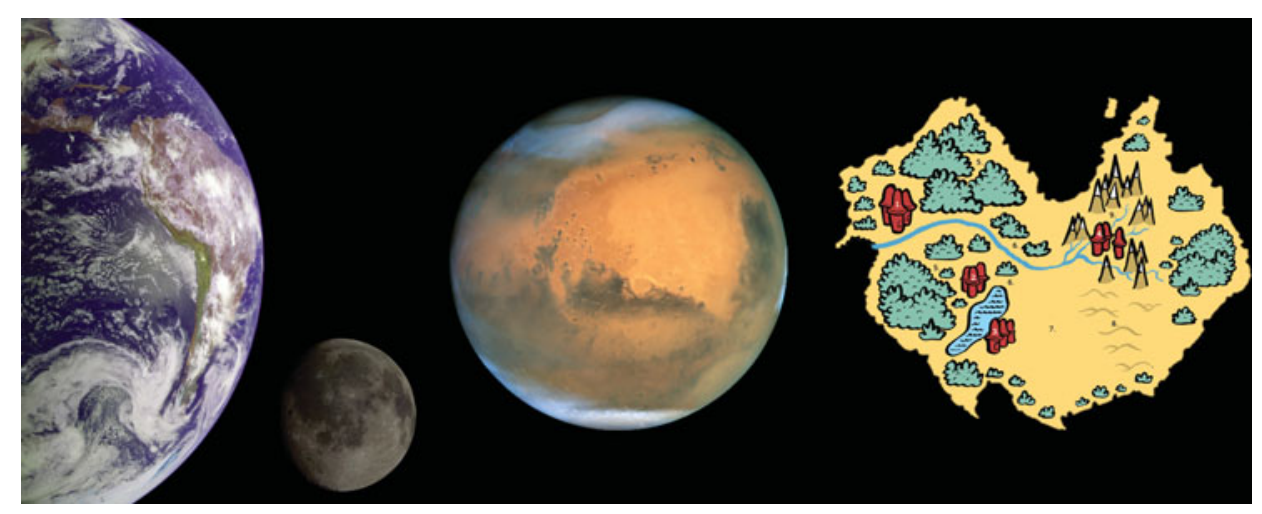

Fig. 1. We learn about planet Earth by comparing it with other planets, including a non-existent planet Mundus that simplifies system Earth for the benefit of primary education. Images not to scale. Earth and Moon: image GPN-2000-001437 taken by Galileo on its way to Jupiter, 1992, courtesy JPL. Mars: image opo0124a taken by Hubble Space Telescope at the opposition of June 26, 2001, courtesy NASA. Mundus: a classroom game that simulates science on a non-existing and simplified planet, map of entire planet.

scientists can contribute to resolving it with simple activities that resemble the process of scientific research and have been developed in the Netherlands but can be conducted anywhere in the world.

Children are curious and actively interrogate their environment by inquiry, testing hypotheses on what they already know, by informal experimentation and by observing and listening to the experiences and knowledge of others. This is strikingly similar to how scientists learn and many related similarities in attitudes, skills and reasoning have been demonstrated, such as curiosity, logical thinking and the ability to recognise fair testing (see Lawson, 2004, and Gopnik, 2012, for reviews). Engaging in questioning and experimenting is not merely important for cognitively more talented children (regardless of how talent is defined and measured). Instead, it is considered important for all children to acquire flexible strategies rather than a set of facts for their lives in a complex world. For example, most people would benefit from having one or more strategies to formulate and address questions about choosing healthy food in the supermarket, or choosing between default or green energy. It is therefore beneficial for society to stimulate school children to develop a basic scientific attitude.

However, in many countries formal education discourages such active attitudes regarding science and technology (e.g. Herwitz \& Guerra, 1996). For example, in the Netherlands, only about $4 \%$ of children's time in class is dedicated to technology, which is low compared to the $10 \%$ in primary schools in other northwestern European countries (PISA, 2006). Moreover, the quality of this time is often limited to demonstrations of a principle or to fully prescribed 'cook book' experiments, rather than an investigation that requires or demonstrates curiosity, question asking and problem solving. Often, there is only one hypothesis that is to be confirmed by the children with the prescribed experiment or through demonstration by the teacher. There is considerable empirical evidence that this teaches pupils little about how science is done. On the contrary, it encourages reliance on an authority, i.e. the teacher, the book or the internet, and this lowers motivation and may even encourage data fabrication (Lawson, 2004). Teachers, scientists and industry increasingly recognise this problem and advocate teaching of problem-solving strategies and creative skills that can lead to new applications of knowledge, processes that are also essential to science. Such skills are currently framed as 21st century skills, but of course they must have been important skills in the entire history of mankind.

The problem of how to implement a stronger focus on teaching such skills is a complex one, however, because at the same time the entire educational system is increasingly held accountable for, and even financed or penalized based on, students' performance in standardised tests. As such tests usually measure factual content knowledge and publishers develop educational materials tuned to such exam programmes, it has been suggested that offering science content courses to teachers would partly solve the problem (e.g. Diamond et al., 2014). However, such 'solutions' offer very little in terms of helping children acquire a scientific attitude and skills (Lawson, 2009). Scientists, on the other hand, do have a scientific attitude, creativity and skills, so could they contribute to a (partial) solution to this problem?

\section{Beneficial involvement of scientists in primary education}

A typical response by scientists to scientific illiteracy has been to give public lectures, develop lessons focused on their research subject and perhaps visit schools. Recognising that a more coordinated effort would be desirable, most universities in the Netherlands developed science education hubs (www.wetenschapsknooppunten.nl) over the past few years that target primary education (age 6-12) and the first years of secondary education (age 12-14). This is an important age 
group as there is compelling evidence that children develop a poorer academic attitude to, fewer skills in and less interest in science and technology if they are not exposed to science and technology teaching before the age of seven (de Vries et al., 2011).

Successful science and technology education also requires teachers who understand the importance and relevance of science and technology, and can convey to their pupils that doing science is an interesting, beautiful and fun experience. Most importantly, in order to teach the process of science, teachers need to feel confident and in control, even when that process may lead to unexpected results that are hard to explain or to perceived chaos in the classroom, and teachers often lack this confidence in their own abilities when it comes to science (Walma van der Molen et al., 2010). This implies that professionalisation of teachers is another important task for science education hubs, and indeed there is evidence that such professionalisation leads to higher achievements of pupils (e.g. Herwitz \& Guerra, 1996; Lawson, 2004). In this paper we will report on our experiences.

We aim to teach science in the way it is practiced, focussing on what we consider to be the three important aspects of natural science that can readily be understood by children and laymen. These are asking questions, generating and testing alternative hypotheses based on available empirical evidence, and collecting new evidence by controlled experimentation (e.g. Chamberlin, 1890; Platt, 1964; Kleinhans et al., 2005; Lawson, 2009).

\section{Approach}

Ideally, the approach followed in the science education hubs and in higher education for teachers is evidence-based. However, the question of how pupils and students effectively gain a scientific attitude and basic skills has not been entirely resolved and is still actively researched. Nevertheless, there is, fortunately, sufficient evidence and experience on how to support teachers and expose pupils to science and technology (reviews in Lawson, 2004; van Keulen \& Sol, 2012; Diamond et al., 2014; van Wessel et al., 2014).

The current study partly relies on scientific action research in the social context of the classroom. Mutual cooperation between earth and planetary scientists, educational scientists and teachers involves systematic observation and analysis of a problem (how to improve the curiosity and intrinsic motivation of children to learn and discover) and the design and evaluation of activities in order to implement changes in educational practice. Using this approach we report on two freely available classroom activities that proved successful in teaching earth science to primary school children and teachers. The first is Expedition Mundus, a classroom game that simulates science as children find out answers to questions and solve problems about a non-existent, simplified planet based on sources of information. This game was not developed as part of a research project but its use in the classroom was incorporated in the action research.

The second activity is experimental investigations of terrestrial and Martian rivers and deltas in a sandbox, which explicitly follow the empirical cycle (discussed later). Combined with investigations using Google Earth, Google Moon and Google Mars, these experiments stimulate linking surface morphology with formative processes as well as discovering important characteristics of Earth compared to other planets. Along similar lines, Herwitz \& Guerra (1996) report on impact cratering experiments conceived and designed by pupils themselves after seeing imagery of Mars.

Both activities are sufficiently simplified in the sense that technical jargon is avoided and specialised knowledge is unnecessary. The subjects are familiar enough to teachers to be useful for them, yet sufficiently sophisticated to gain the insight that science asks questions, creates alternative explanations and rigorously tests these. Both activities have been offered at science education hubs. In addition, science education hubs offer these activities as part of professionalisation courses for teachers. Below we detail both activities and discuss their learning outcomes for children, teachers and scientists.

We conducted our work at two levels. Firstly, we did our activities in schools in close interaction with the teachers and pupils. Secondly, we observed the activities and the responses of pupils and teachers. For the Mundus game, this was done through collection of anecdotes from the involved authors, other scientists and interviews with teachers and, in separate sessions, teacher educators. For the experiments we observed and documented in video and writing the actions and conversations with and among the pupils and teachers, and analysed in particular how the pupils formulated and improved their results in the process of doing science.

The process of science was simplified to the form of the empirical cycle, such that young children in primary schools can apply it. The empirical cycle as used in education derives from the hypothetico-deductive method of science, extended with the abductive generation of hypotheses (Lawson, 2009; Kleinhans et al., 2010; van Wessel et al., 2014). The empirical cycle is similar enough to the design cycle to be able to apply it to technology and design as well. The example in Table 1 illustrates the level at which children understand the empirical cycle as was evidenced by our observations of how they later used the empirical cycle in their own investigations in the sandbox or with other set-ups (Bastings, 2012). The level at which pupils understood the empirical cycle is that they experienced how they got stuck and did not know how to proceed when they skipped a step in the cycle, whereas they were able to conclude their investigations when the procedure was followed correctly. We recognise that in the process of real science there are many 
Table 1. Empirical cycle illustrated with an inquiry into the answer of a question in the Expedition Mundus game and in a controlled experiment on a food item favoured by many children: pancakes, Dutch style, made of flour, milk and egg.

\begin{tabular}{|c|c|c|c|}
\hline & Step in empirical cycle & Example inquiry: Expedition Mundus & Example experiment: pancakes \\
\hline 1 & Wondering, problem, questions & $\begin{array}{l}\text { B19: Which town on Mundus is at the highest } \\
\text { altitude? }\end{array}$ & Why do we put egg in pancakes? \\
\hline 2 & $\begin{array}{l}\text { Activate foreknowledge, abduce } \\
\text { hypotheses, deduce testable } \\
\text { consequences }\end{array}$ & $\begin{array}{l}\text { Fig. 2B: The town that is drawn the largest is } \\
\text { the highest. Alternative: rivers flow downhill. }\end{array}$ & $\begin{array}{l}\text { To make pancakes firmer, to cause binding, } \\
\text { because egg stiffens when heated. }\end{array}$ \\
\hline 3 & $\begin{array}{l}\text { Methods: design the experiment, } \\
\text { including a control and } \\
\text { measurement methods }\end{array}$ & $\begin{array}{l}\text { Look for sources with towns and information on } \\
\text { elevation. }\end{array}$ & $\begin{array}{l}\text { Bake pancakes with and without egg in } \\
\text { otherwise the same conditions. }\end{array}$ \\
\hline 4 & Conduct the experiment & Find the highest town and find its name. & Feel and taste the differences. \\
\hline 5 & Draw conclusions & $\begin{array}{l}\text { The answer is checked by editor: 'Nuki-wom is at } \\
\text { the highest altitude.' }\end{array}$ & $\begin{array}{l}\text { (In experiments, teachers should not give } \\
\text { answers. The reader may try this at } \\
\text { home.) }\end{array}$ \\
\hline 6 & Present or publish the result & $\begin{array}{l}\text { If correct, the answer card is published on a } \\
\text { paper with the name of the pupil on it. }\end{array}$ & $\begin{array}{c}\text { Tell the class about the results; make a } \\
\text { poster or a projected presentation. }\end{array}$ \\
\hline 7 & $\begin{array}{l}\text { Contextualise, put results in broader } \\
\text { perspective and raise new questions }\end{array}$ & $\begin{array}{l}\text { Answer cards are new sources to answer more } \\
\text { difficult questions and develop a world image } \\
\text { of Mundus. }\end{array}$ & Refer to other food items with egg in them. \\
\hline
\end{tabular}

iterations along parts of the empirical cycle, and indeed this complexity was experienced by the pupils as they did their own experiments, which we found in our conversations with pupils and teachers.

\section{Expedition Mundus: a classroom game that simulates science}

To help teachers and pupils to get acquainted with 'how scientific research works', we conceived the classroom game Expedition Mundus (Fig. 2). This game was developed by the Young Academy (De Jonge Akademie, 2014) of the Royal Netherlands Academy of Arts and Sciences (Koninklijke Nederlandse Akademie van Wetenschappen) and De Praktijk, developers of activities for science education and communication. The game has proven to be an efficient and stimulating tool that can act as a launch pad for further science teaching in schools and in teacher education. An English translation is now available and can under certain conditions be translated to other languages (see www.expeditionmundus.org for conditions). The game includes an extensive manual written for, and tested by, teachers and the background information needed for a translation.

Expedition Mundus is a puzzle and role-playing game in which the players have to find the answers to research questions they receive (on cards) in the available resources distributed around the classroom. Expedition Mundus contains research questions, information sources and answers to the research questions. After their answers have been reviewed and approved, the pupils publish them and the answers then become part of the resources. Answers to more complicated questions yield more points. Whoever has the most points wins and the group as a whole acquires more knowledge and understanding of planet Mundus and a tacit understanding of the process of science.

The game is briefly introduced with instructions and, for the younger ages, an introductory read-aloud story. The information sources are (double) page sized and research questions and answers are printed on small cards. Students collect research question cards from the teacher and move around the classroom to look at information source posters. For many questions, especially the harder ones, the pupils need to integrate information from multiple sources. Pupils can seek out these sources and also ask other pupils whether they know where to find certain information. When they think they know a correct answer, they go back to the teacher for peer review; if their answer proves correct, the students are allowed to publish the corresponding answer card on their publication sheet. This answer card, in turn, provides all players with the new information that they need for the more difficult questions.

The questions about Mundus come at four levels of increasing difficulty: a start-up set for primary education and three subsequent levels that can also be used in secondary education. Simple questions are, for example, 'Which town on Mundus is at the highest altitude?' and 'Mundians use the word pi a lot. Do they use it when they're happy or when they're unhappy?'. More complicated questions require several sources of information and logical reasoning for an answer. The most complicated 

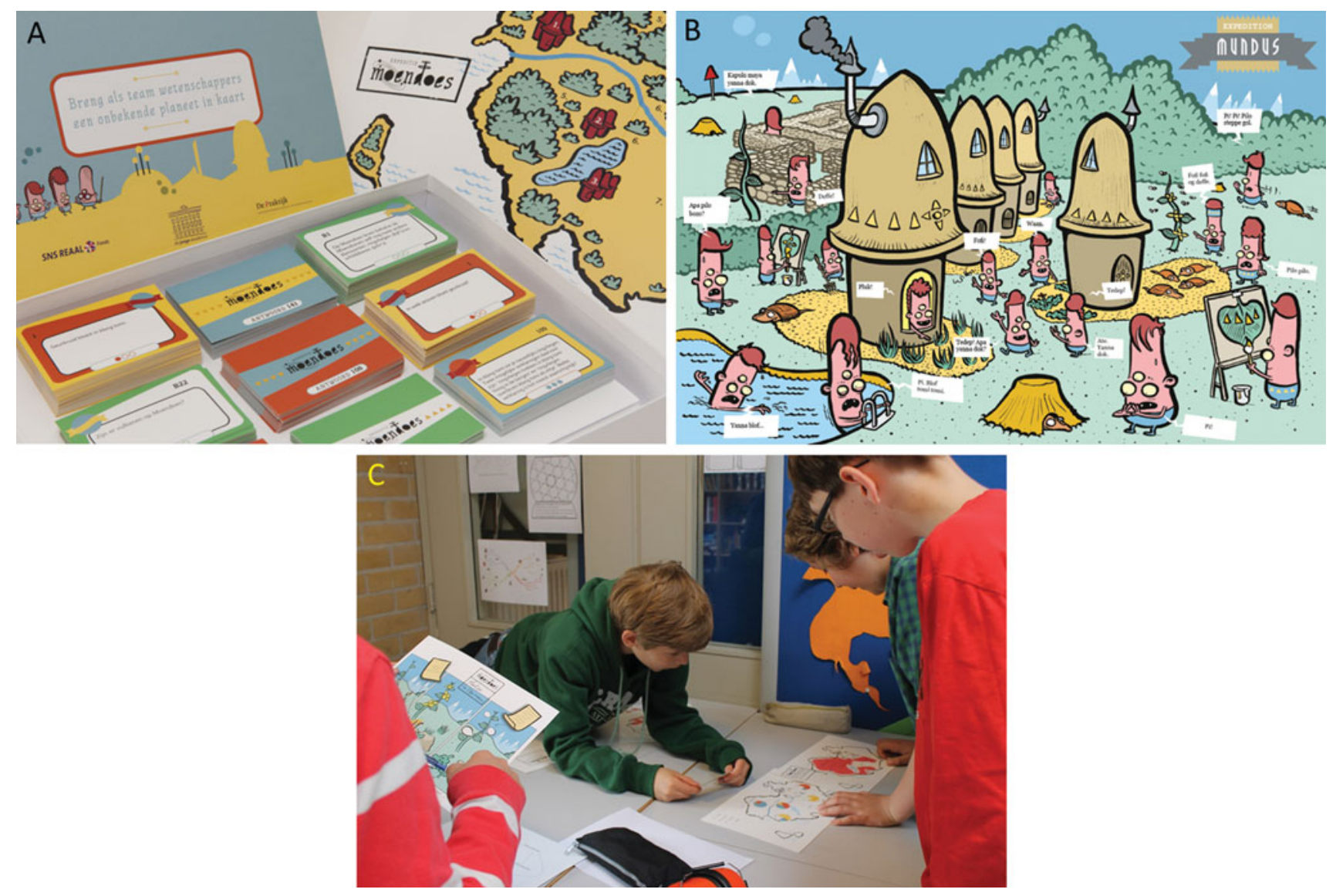

Fig. 2. The classroom game Expedition Mundus. A. The game consists of sources, such as the map in the background, question cards and answer cards. To answer the questions pupils must research the available information and often combine sources to infer the answers. B. Ground view on Mundus, one of the sources, showing different species, aspects of culture and hints of the climate. C. Children play Mundus in class, studying and combining information from sources to find answers to research questions.

questions also require information from answer cards of simpler questions to be resolved. An example of a more complicated question is, "There are spiceherb seeds in the soil of the hills on Mundus. What region of Mundus do these seeds mainly come from?' To resolve this, first a map is needed that shows the location of the hills and the distribution of plant species on the planet, including the possible sources of the seeds. It turns out that the spiceherb species does not grow in the hills but does occur northeast and northwest of the region. In order to resolve which single area is the source, pupils need to combine a Mundian biology book showing that the spiceherb produces its seeds in the season called 'klang raf raf', and a chart of measured wind speeds and directions for a few years, showing that high wind speeds from the northwest frequently occur in the right season. Occasionally pupils just gambled and pick one of the two possible directions from the first-mentioned source. However, when the initial answer was wrong and they investigated further, the question was answered correctly by the pupils, showing that they can do complicated logic of inference and combination of sources.
The teacher manual contains instructions for playing the game in the classroom, all the 'facts' about Mundus and the Mundians, a basic analysis of the similarities and differences between playing the game and doing science, instructions for possible follow-up activities and for writing a research report that a Mundian scientist could have written about the students' neighbourhood, a basic scientific experiment following the empirical cycle in which students investigate the effect of eggs in a pancake recipe and two stories (an introduction and a wrap-up) to be read aloud to younger students. After the game, teachers can have a structured classroom conversation with their students. In this conversation they ask the students to talk about their experiences and link these to short explanations of important aspects of scientific practice, such as hypothesis testing on the basis of the available evidence, collaboration and competition, and publication. For the younger ages, teachers read the wrap-up read-aloud story and use that to explain a few core competencies for scientists. In our classroom conversations with pupils over 8 years we found that pupils nearly always actively contributed to two topics: the tension between competition for 
points and collaboration for joint knowledge, and the tension between the necessity and risk of specialisation.

\section{Learning about rivers and deltas on Earth and Mars with sandbox experiments}

\section{Sandbox experiments in planetary science}

Here we briefly exemplify how sandbox experiments are currently used in earth and planetary science to gain insight, which underlies the science education brought to primary schools. We explain which types of experiments in particular were suitable for primary education and which were not. The art of experimental creation of fluvio-deltaic sedimentary systems at a small laboratory scale goes back at least to 0sborne Reynolds (Reynolds, 1889), who is most famous for his turbulence studies and the Reynolds number. The obvious advantage of a reduction of the characteristic spatial scale of a system is not merely easier observation, but a reduction of the characteristic formative time scale. In other words, deltas at the scale of a table form much faster than deltas on Earth or Mars. Scientists have recreated a wide range of fluvio-deltaic systems such as alluvial fans, valleys, fan deltas, vegetated fans, deltas and rivers with various patterns, braided rivers, meandering rivers and tidal basins such as found in the Wadden Sea (see Paola et al., 2009, and Kleinhans et al., 2014, for reviews).

Some fluvio-deltaic systems are remarkably simple to form in the laboratory and are therefore very suitable for exploration, controlled experimentation and hypothesis testing by unskilled pupils and students. Fluvial systems that are strongly degrading or aggrading are particularly suitable because they do not require a subtle balance between erosion and sedimentation, and tuning of sediment feed rates to achieve this balance. An approximately constant flow from a garden pond pump or the water mains is sufficient. Examples are erosive valleys, breaches in dikes or coastal barriers as represented by a sand dike, braided rivers, alluvial fans and deltas when sediment supply is ample (Paola et al., 2009; Kleinhans et al., 2014). In principle, these experimental landforms form with any sand, but poorly sorted, coarse sand works best and also creates sorting patterns that highlight the morphology and raises new questions (Kleinhans et al., 2014). Other fluvio-deltaic systems, such as meandering and channelised delta systems, are surprisingly difficult to form in the laboratory. For such systems, the strength of the banks is an important factor for channel pattern and dynamics. Bank strength can be enhanced by cohesive material or real plant sprouts (Kleinhans et al., 2014), but such experiments require much more time and precision, and are therefore not suitable for the classroom.

The actual process of science is rather complicated. In the case of the Martian deltas, for instance, there is an intricate combination of inferences from imagery, a host of other inves- tigations, some of which are consistent with a short-lived delta, analysis of the similarity scaling of processes and geometries between experiments and nature, and so on. Nevertheless, the basic empirical cycle used in education is recognisable (Table 1).

First, the cycle begins with questions, for example about past hydrological conditions on planet Mars: how much water is needed to form fluvio-deltaic landforms on the Martian surface, and how long the fluid water was active for. One type of crater lake deltas of which a few tens have been identified on Mars are referred to as 'stepped fans' in planetary science. These deltas consist of several sedimentary 'terraces' of increasingly smaller radius. Possibly the climate was warm and wet during the formation of these landforms on the basis of interpretation of imagery of the planetary surface. The alternative explanation is that outflow was triggered by a meteorite impact or localised volcanic activity that generated heat. Interpretation of the imagery of the planetary surface was done to partially test the 'warm and wet' hypothesis.

Second, on the basis of foreknowledge one then infers hypothetical answers to the question by abduction (sometimes called retroduction) (Kleinhans et al., 2005, 2010; Lawson et al., 2009). For Mars the alternative hypotheses are that the terraces formed by wind-generated wave action in long-standing lakes (Di Achille et al., 2006), which implies a long-lasting warm and wet climate, or the terraces formed in the morphodynamic process of a single outflow event. These different interpretations arose because terrestrial, geological experience of Holocene delta formation was directly applied to Mars on the one hand, whilst pilot experimentation suggested a more rapid mechanism.

Third, the hypothesis, or preferably contradictory alternative hypotheses (Chamberlin, 1890), is used to predict by deduction what would happen in a fair test. This led to two further alternative hypotheses. Perhaps the steps were formed under rising lake levels (Kraal et al., 2008) or by terrace formation by waves at several discreet stationary lake levels (Di Achille et al., 2006).

Fourth, this leads to formulation of the simplest possible questions that isolate a single variable, and the design of experiments to do so. For the Martian deltas this meant repetition of the same conditions except for the water level control. The design of the experiments was based on the physics of flow and sediment transport, and the imposed geometry of the experiments was based on observations of impact craters on the Moon and Mars (Kraal et al., 2008; de Villiers et al., 2013).

Fifth, after doing the investigation specific conclusions can be drawn. As the crater in each experiment filled with water, sediment deposited in the form of a regressive delta. Pulses of sediment from upstream valley wall collapses caused the formation of the steps onto the regressive but rising fluvial surface of the delta.

Sixth, the conclusions are generalised by induction. For the Martian deltas we reported in the literature that all stepped fans on Mars likely formed in a brief event, for which potential 
triggers are already known, and that this explains the observations more parsimoniously than a warm, wet climate. This conclusion is further supported by experiments of contrasting fan types that we also created, in particular classic Gilbert-type fan deltas (de Villiers et al., 2013) and alluvial fans (van Dijk et al., 2012). These three fan types can easily be created in any sandbox with water depth in the receiving basin as the only variable.

Seventh, this will raise new questions and new testable hypotheses, as will the process of putting the results into a larger context and thus the cycle continues while knowledge builds up. For the Martian deltas our further research addressed the questions of timing and triggering of delta formation (Hauber et al., 2013), and the source and expulsion of groundwater (Marra et al., 2014). Below we relate how the empirical cycle as a process to answer questions can be applied by children by doing experiments.

\section{Sandbox experiments in primary schools}

In one school (documented in Bastings, 2012; van Keulen \& Sol, 2012; van Wessel et al., 2014) we proceeded in the following order. After playing Mundus and baking pancakes, we introduced the subject of rivers and deltas with images of Earth and Mars, and we showed how we investigate these systems with sandbox experiments. This raised many questions.

We then asked pupils to compare a number of fluvio-deltaic systems and different surface morphology in Google Earth and Mars, which surprised children and therefore raised questions. Surprises included differences in shape but also conflicts with foreknowledge and perhaps misconceptions. For example, some deltas on Earth were found to have many clearly identifiable distributary channels, whereas some deltas on Mars showed no channels at all beyond the feeder channel. In addition, their own sense of place of the immediate surroundings or holiday locations raised such questions about small rivers. For example, the lack of meandering of the small stream near the school was contrasted by a pupil to the meandering shown in a small stream on imagery. This was followed by collaboratively and collectively formulating hypotheses that explain the observations. Similar experiences for planetary imagery are reported in Herwitz \& Guerra (1996). For the best results pupils should be able to feel free to forward any hypothesis, even ones that may seem ridiculous. In primary schools a majority of the children readily participate in this process but in secondary schools and higher education our experience is that students often tend to hold back, presumably because of peer pressure (also see Lawson, 2009).

In the one school mentioned earlier, we had children design their own sandbox, starting from the principle of the hydrological cycle and the design requirement that the sand did not spread through the classroom (Fig. 3). This triggered interest and motivation to learn about abstract concepts and procedure, such as how to calculate volumes, because the entire volume of water in the flume should not spill out of the shallow overflow basin onto the floor. Many other interesting points arose during the design and construction, including technical aspects of carpentry, the operation of the garden pond pump, reasons for leaks in the sandbox and measurement methods for flow velocity and flow discharge. By deliberately allowing the children to make mistakes and unearth their misconceptions, they discovered fundamental laws of physics. For example, a first test of the set-up (without sand) did not lead to flow in the basin because it was set horizontally. When asked, one pupil explained that she expected the river to flow over the surface because it was at speed and would conserve this speed, and she motioned with her hand that the wetting front of the new river in the empty sandbox should have moved downstream. However, by doing the experiment the pupils quickly discovered that water needs a slope to flow downstream, and that a small gradient is sufficient to obtain mobile sediment of enough intensity to lead to the desired morphological change in, say, 10 minutes.

Using sandbox experiments, children formulated questions and found which of these were open to experimental investigation. Moreover, they learn to recognise fair testing with a control experiment to arrive at an answer and also to recognise situations where this was not done properly. For example, they formed a Martian stepped fan delta in two different depths by digging a shallow hole and a deep hole, the crater, in the sand and supplying enough water from about half a metre away from the rim of the hole to fill it. The flowing water transported the sand into the crater to form a delta whilst the water level in the lake rose. This raised questions about how to compare it to imagery of Mars. Furthermore, the pupils correctly used a number of words and concepts that are in fact basic jargon of fluvial morphodynamics, such as 'meandering', 'braiding', 'discharge', 'dike breach' and 'channel' as opposed to 'canal' (Bastings, 2012).

Many other simple experiments are possible in a sandbox. A popular experiment in the Netherlands is, not surprisingly, flooding river dikes. For example, pupils tested the hypothesis that higher dikes are better at preventing flooding. Several surprising things then happened in the experiment (Fig. 3): the sand dikes failed, not because they were overtopped, but because they fluidised after saturation by water, which illustrates groundwater flow and geotechnical processes. Such unanticipated events in an experiment falsify the initial hypothesis. These often trigger the biggest leaps in science and are very valuable events in a class. Furthermore, the sand eroded from the dike and river deposited in the form of a splay, which showed striking similarities with dike breach splays found in fluvial plains such as that of the Rhine Meuse delta, e.g. below the village of Huissen in the Netherlands (51 $55^{\prime} 42^{\prime \prime} \mathrm{N}$, $5^{\circ} 56^{\prime} 45^{\prime \prime} \mathrm{E}$, also see LIDAR-data on www.ahn.nl). Follow-up experiments designed by the pupils themselves 

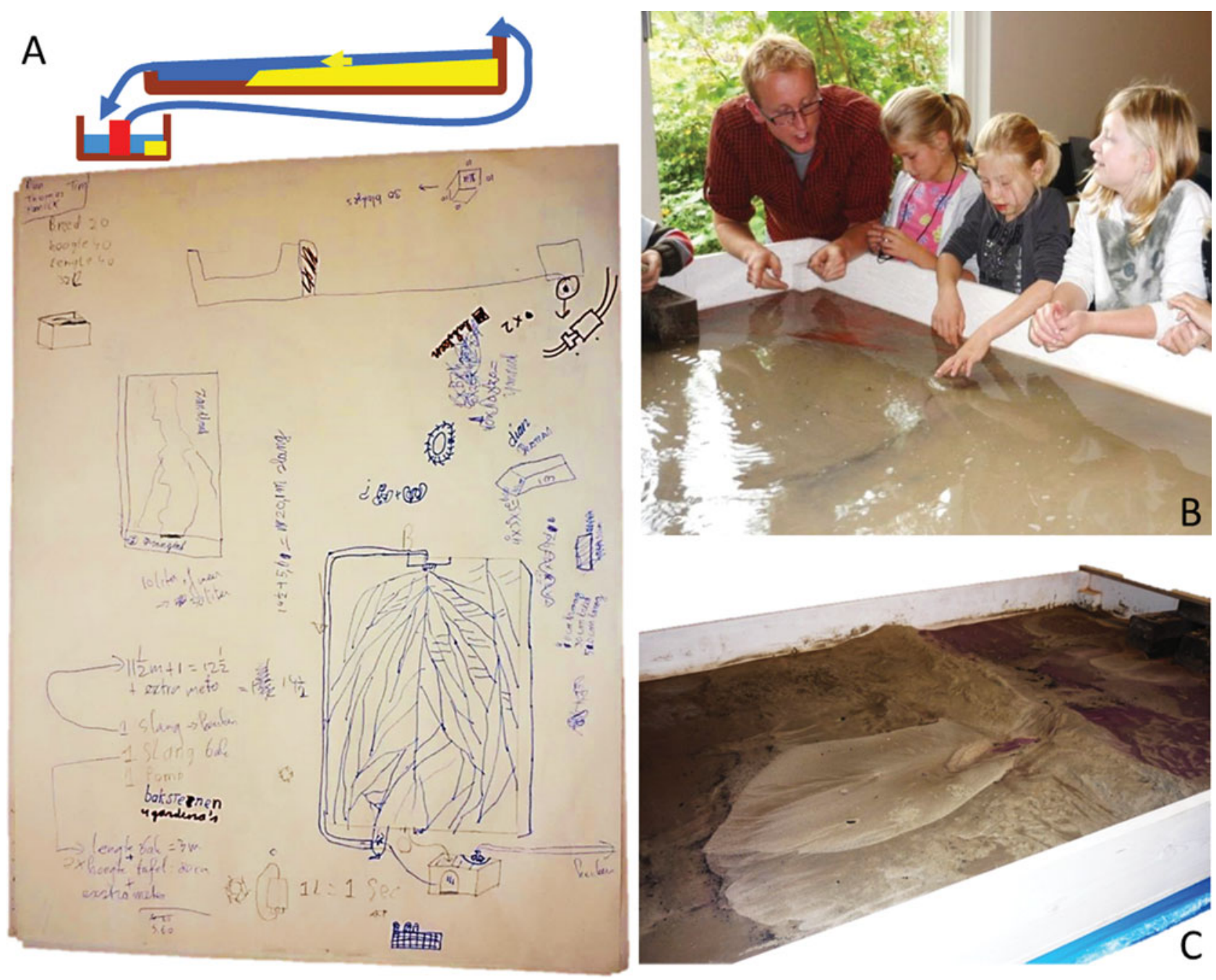

Fig. 3. A set-up of sandbox experiments in Primary School De Klokbeker, Ermelo. A. Example of the design of the sandbox and the hydrological cycle simulated with the pump by pupils. B. Delta experiment, showing explanation by a scientist and impatience to manipulate the experiment in a pupil. C. Dike breach experiment (from right to left), showing a scour hole and splay that pupils compared to real splays in Google Earth.

focused on preventing groundwater seepage and strengthening dikes by growing vegetation on them. These experiments inspired many new questions about natural fluvial landscapes, human settlement, spatial planning and dike design. Furthermore, classroom discussions put the new tacit understanding of flood protection into the rather abstract context of the last major flooding of the Netherlands in 1953, which had been taught in history class a few weeks earlier. This shows that the scientific classroom activities led to questions by pupils about related subjects in wider contexts, including contexts taught in other lessons unrelated to our activities (Bastings, 2012).

Furthermore, we saw indications that the planetary perspective stimulates pupils to re-evaluate their understanding of planet Earth. This followed a discussion on the morphological effects at the planetary surface of the nature of the hydrological cycle, done with children who had completed Expedition Mundus, the sandbox experiments and other science and tech- nology teaching. After a brief introduction to the hydrological cycle, which the pupils were already familiar with, a complication was introduced: the low atmospheric pressure at the surface of planet Mars does not allow the presence of fluid water, yet images of the planetary surface clearly show morphology formed by fluid flow. Given the absence of other fluids and the presence of water ice, the pupils were asked to formulate and draw solutions for the paradox. Creative ideas arose, some of which can also be found in the scientific literature. Three examples of solutions postulated by the pupils are as follows. First, the water may originate from the meteorites that formed the craters observed at the surface (e.g. Morbidelli et al., 2000). Second, the climate was different in the past (e.g. Baker, 2001). Third, a giant water planet orbiting the Sun between Earth and Mars exploded, which is perhaps a reference to the myth of Atlantis. The ensuing discussion put the knowledge of the hydrological cycle, previously presented as a hard, universal fact, into a wider perspective. The past and present conditions of 
planet Mars forced the pupils to re-evaluate the concept to assess which parts of the foreknowledge remain hard facts and which are more situational. In short, the planetary perspective helped and greatly motivated pupils to expand their understanding of planet Earth.

\section{Discussion of learning outcomes for primary education and benefits to science}

\section{Learning outcomes in school: improving attitude and skills}

We found from a few hundred occasions of playing Expedition Mundus in a team of teachers and in class in Dutch schools that there are three immediate effects (Verkade \& Kleinhans, 2014). The first is that the game is fun and, by inference, so is science. Most children energetically participated in it and many pupils and teachers remembered it years afterwards. Clearly, the game appeals to their natural curiosity and intrinsic motivation to play games (Fig. 2). The second effect is that the game makes clear that science is about asking questions and systematically investigating these, which one can do in every subject and discipline. The third is more subtle: having done the game, pupils and teachers have a more articulated and more accurate view of what science is. These preliminary conclusions are based on our collective experience, pending a more formal investigation of the short-term and long-term effects of playing Expedition Mundus or other activities on scientific attitude.

Pupils who did experiments learned about many technical and scientific issues, as illustrated in the previous section, but more importantly learned about the practice of science (e.g. Bastings, 2012). Our three-stage project allowed this observation: following the pancake baking exercise the group did a closely supervised experimental investigation, after which the pupils did another experimental investigation following the empirical cycle. In this last step it became apparent that they had understood parts of the practice of science and required less help to complete the empirical cycle, which included a presentation of results following the empirical cycle in a poster session. Furthermore we saw that pupils learned to formulate causal questions in the context of planetary science (such as 'What is the effect of $\mathrm{X}$ on Y?') and learned to use the basic technical language of planetary science and of experimental equipment and measurement (Bastings, 2012; van Keulen \& Sol, 2012), in agreement with Herwitz \& Guerra (1996).

Observations by (educational) scientists and teachers showed on many occasions that the presence of a scientist stimulated the children's curiosity, encouraging them to describe, inquire and reason about what they were seeing (in agreement with Herwitz \& Guerra, 1996). We observed that the experiments strongly increased the number of questions that pupils asked. The questions and hypotheses raised by pupils also became more complicated as the scientist pointed at certain phenomena, explained certain mechanisms and raised further questions about them. By doing this the scientist modelled the ways he/she 'looks' at the world, is curious about it and reasons about it. We also have anecdotal evidence that experimentation and design stimulated pupils' creativity, although an operational definition of creativity is lacking. A perhaps undervalued but important aspect of science is the understanding that scientists gain from research activities such as building models and doing experiments (De Regt \& Dieks, 2005). Having done that as part of academic training, similar experiments and models reported in literature are more understandable. This was also the case in the classroom, where from interviews with pupils it became evident that they had gained understanding of the difficulties of flood protection by dike construction. They did not gain such conceptualization from a mere presentation of facts about a historically important flooding. This is an illustration that pupils and students learn efficiently by experimentation.

Clearly, age and development as well as the inquisitiveness of pupils determine the level of science teaching that can be reached. In the first place, the science should link to the prior knowledge of pupils, which grows over time. Second, the level of abstraction depends on age. Pupils aged 4-7 appeared to have difficulty dealing with scenarios in the process of hypotheses generation, for example with asking 'what if' questions (e.g. Lawson, 2004). Many pupils in this age group are able to recognise fair and unfair tests in simple set-ups, but based on the amount of dependency on the scientists with formulating and refining hypotheses, they are unable to devise experimental set-ups that are fair tests of isolated variables (also see Lawson, 2004). Older children appear to be increasingly adept at hypotheses generation and dealing with multiple hypotheses, and are more often able to design fair test situations in relatively simple experimental settings.

The empirical cycle as a heuristic tool poses challenges to primary school teachers. In the first place, a large group of children conducting their own experiments in small groups is potentially more chaotic than classical instructive teaching. The teacher, then, needs to be in control at a different level: that of a fundamental understanding of the empirical cycle as well as a shift in focus from learning content (e.g. delta formation) to the learning process (skills and attitude). Our most successful projects were therefore those that kept the science very close to subject matters that teachers are familiar with, for instance food preparation (the pancake examples with the Mundus game) and playing with water and sand. Moreover, the phase of formulating questions requires a teacher to be skilled in asking higher-level questions that help the pupils in searching for their own answers. Likewise, steering the design of fair testing is not simple. The experimental method is clearly limited to phenomena that can be investigated by pupils, which excludes many subjects that pupils ask deep questions about, such as the origin of planets. Involvement of scientists may be 
of significant help here because of their factual knowledge and understanding of research approaches, but perhaps even more because scientists may model the academic attitudes and convey their passion for science to the children. A typical example illustrating such academic attitude of children in our study is the response on interference (of a school staff member not involved) in the experiment: 'Hey, what are you doing, now our experiment is not fair and we need to do it again'. The teachers involved in the sandbox experimentation are now actively transferring their knowledge, experience and understanding to other teachers in their school and to other schools in the region. Many other studies empirically demonstrated the positive effect and importance of the science knowledge and skills of teachers, preferably academically trained, not only because this knowledge is to some extent transferred to the pupils, but also because it positively affects the self-efficacy of the teachers (e.g. Diamond et al., 2014; Walma-van der Molen et al., 2010).

A systematic, well-designed study of educational principles and learning outcomes beyond the collection of anecdotal evidence remains to be done. It remains poorly investigated to what degree the classroom activities reported here affect the quality and quantity of learning in pupils and improve the selfefficacy of teachers. If they are found to work, then in order for larger scale implementation to occur, another practical hurdle must be taken: how to measure the progress in the academic skills of individual pupils on a large scale. The present national science and technology examination of primary school children is limited to the reproduction of facts rather than the skills we aim to have them achieve, and is therefore not suitable as an instrument in effectiveness studies. Instead, observable measures are needed that can show whether pupils were able to tackle novel problems by applying the combining of sources of information to answer questions, the formulation of researchable questions and the empirical cycle as a method of investigation. Such observation requires teacher understanding of the process of science.

\section{Benefits for scientists and higher education}

In our experience there are direct benefits for academics that embark on science and technology teaching on the level of primary education. In the first place, scientists are exposed in a relatively safe environment to laymen and children that provide direct feedback on the science communications. This allows scientists to hone their skills in communicating about their science with the public. Second, we are forced to simplify and contextualise science to the level of primary education, which helps scientists to develop a deeper level of understanding of the scientific enterprise. This understanding may help their further development, but is also particularly useful in teaching in higher education. Both points were also found to be the case in the projects at the Science Education Hub of the Radboud
University in Nijmegen (Coppens et al., 2012), where scientists compete annually for research funding that can be conducted together with pupils in schools.

Perhaps most importantly, many, if not most, Bachelor and Master programs in earth sciences emphasise the subject matter from basic knowledge to advanced concepts as well as skills such as mapping in fieldwork and programming, but hardly spend any time on the more difficult logical reasoning skills, learning to ask empirical questions, alternative hypothesis generation and learning how to set up fair tests of the hypotheses. This deficiency commonly surfaces as late as in the first stages of MSc thesis research. The rhetorical question that needs to be posed is why these programmes spend much time on basic knowledge that can relatively easily be acquired, while expecting students to develop much more difficult and critical academic attitudes with very little formal training and guidance. An explicit exposure of earth scientists and lecturers to didactic and philosophical understanding of these fundamental aspects of science can only be beneficial for university teaching and science contributed by students. There are also indications in the science education hubs and reported in literature (e.g. Herwitz \& Guerra, 1996) that university student involvement in science education for primary school children can have positive effects on curiosity and engagement. Such self-reflection on the practice of science, and how we teach this, is a significant windfall from the involvement of scientists in primary and secondary teaching.

We argue that this should have consequences for university management and evaluation committees. Universities are increasingly expected to demonstrate their impact on society. One way of having an impact is to help to improve science and technology education at all levels. This does not mean that all scientists ought to rush to primary schools now, but it should be valued that some of the faculty contribute in this manner. Furthermore, lecturers at Dutch universities are required to obtain a teaching qualification as a pendant of their $\mathrm{PhD}$. Advanced teaching skills can be acquired by teaching at primary schools. Here, teaching is at the most challenging level for scientist, as it requires the highest degree of simplification and clarity. Lecturer evaluation criteria should therefore include this as an option.

\section{Conclusions}

Young children are often interested in questions related to earth and planetary science, yet science and technology hardly receive any attention in primary school, and if they do, the focus lies on teaching facts rather than having pupils engage in the empirical or design cycle. One important cause for this is that teachers are not trained and lack self-efficacy in science and technology teaching, and another reason is the lack of involvement of scientists in primary education. 
We developed and tested primary school activities that cover basic aspects of science: asking questions, developing alternative and testable hypotheses, and rigorous testing based on available evidence or new experiments. The idea at the core of the activities is that we focus on the process of science rather than its finished products or fun facts.

We found that pupils ask more and more complicated questions, and develop research and design skills that they were able to apply in different situations, including the idea of control experiments and the importance of measurement. Furthermore, pupils learned and correctly used a number of words for the earth-scientific phenomena they observed on imagery and simulated in experiments, and applied important concepts of the earth and planetary sciences in different situations.

\section{Acknowledgements}

Two anonymous reviewers are gratefully acknowledged for comments that helped to improve the paper. Many people contributed to Expedition Mundus, including but not limited to 0. Gelderblom (Utrecht University), I. Koopmans (Koninklijke Nederlandse Akademie van Wetenschappen and De Jonge Akademie), C.L. Geraedts (Vrije Universiteit Amsterdam), C.S. Vlek (Groningen University), Y. Matteman (Naturalis Biodiversity Center), M.J. Jansen (De Praktijk), E.A. Crone (Leiden University), M.J.T.H. Goumans (Leiden University Medical Center), A. Sluijs (Utrecht University) and M. van der Putten (Koninklijke Nederlandse Akademie van Wetenschappen and De Jonge Akademie). Funding for the production of the Dutch version, Expeditie Moendoes, was provided by the SNS REAAL Fonds. Many educational researchers and teachers contributed to the sandbox experiments, including Karola de Vries and André Guijs (Primary School De Klokbeker, Ermelo), Hester Kleinhans-van de Kasteele (Primary School De Ontdekkingsreis, Doorn), Mirjam Bastings and Hanno van Keulen (Center for Education and Learning, Utrecht University), and Renske Terwisscha van Scheltinga, Anne Baar, Wout van Dijk, Wietse van de Lageweg and Henk Markies (Utrecht University, Faculty of Geosciences).

\section{References}

Baker, V.R., 2001. Water and the Martian landscape. Nature 412: 228-236. doi:10.1038/35084172.

Bastings, M., 2012. Talent ontwikkelen met wetenschap en techniek. Een beschrijving van talentontwikkeling van kinderen in de context van wetenschap en techniek op Vindplaatsschool De Klokbeker (in Dutch). Utrecht University, Centrum voor Onderwijs en Leren: 23 pp. http://www.uu.nl/ wetenschapsknooppunt.

Chamberlin, T.C., 1890. The method of multiple working hypotheses. Science 15: 92-96.

Coppens, K., Peeters, M., Verhoeff, R. \& Figdor, C., 2012. Opbrengsten en uitdagingen van onderzoekend leren: Een kwalitatieve evalu- atiestudie naar het WKRU-programma 'Wetenschappelijke doorbraken de klas in!'. Radboud University, Wetenschapsknooppunt. http://www.ru.nl/ wetenschapsknooppunt/.

De Jonge Akademie, 2014. Expedition Mundus. http://www.expeditionmundus. org.

De Regt, H.W. \& Dieks, D., 2005. A contextual approach to scientific understanding. Synthese 144: 137-170.

de Villiers, G., Kleinhans, M.G. \& Postma, G., 2013. Experimental delta formation in crater lakes and implications for interpretation of martian deltas. Journal of Geophysical Research 118: 651-670. http://dx.doi.org/10.1002/jgre.20069.

de Vries, M.J., van Keulen, H., Peters, S. \& Walma van der Molen, J.H., 2011. Professional development for primary teachers in science and technology. The Dutch VTB-Pro project in an international perspective. Sense Publishers (Rotterdam/Boston/Taipei).

Di Achille, G., Marinangeli, L., Ori, G., Hauber, E., Gwinner, K., Reiss, D. \& Neukum, G., 2006. Geological evolution of the Tyras Vallis paleolacustrine system, Mars. Journal of Geophysical Research 111: E04003.

Diamond, B.S., Maerten-Rivera, J., Rohrer, R.E. \& Lee, O., 2014. Effectiveness of a curricular and professional development intervention at improving elementary teachers' science content knowledge and student achievement outcomes: year 1 results. Journal of Research in Science Teaching 51(5): 635-658.

Gopnik, A., 2012. Scientific thinking in young children: Theoretical advances, empirical research, and policy implications. Science 337: 1623-1627.

Hauber, E., Platz, T., Reiss, D., Le Deit, L., Kleinhans, M.G., Marra, W.A., de Haas, T. \& Carbonneau, P., 2013. Asynchronous formation of Hesperian and Amazonian-aged deltas on Mars and implications for climate. Journal of Geophysical Research 118: 1529-1544. http://dx.doi.org/10.1002/jgre.20107.

Herwitz, S.R. \& Guerra, M., 1996. Perspectives, partnerships, and values in science education: a university and public elementary school collaboration. Science Education 80(1): 21-34.

Kleinhans, M.G., Buskes, C.J.J. \& De Regt, H.W., 2005. Terra Incognita: Explanation and Reductionism in Earth Science. International Studies in the Philosophy of Science 19(3): 289-317. doi:10.1080/02698590500462356.

Kleinhans, M.G., Bierkens, M.F.P. \& van der Perk, M., 2010. On the use of laboratory experimentation: 'Hydrologists, bring out shovels and garden hoses and hit the dirt'. Hydrology and Earth System Science 14: 369-382. http://www.hydrol-earth-syst-sci.net/14/369/2010./

Kleinhans, M.G., van Dijk, W.M., van de Lageweg, W.I., Hoyal, D.C.J.D., Markies, H., van Maarseveen, M., Roosendaal, C., van Weesep, W., van Breemen, D., Hoendervoogt, R. \& Cheshier, N., 2014. Quantifiable effectiveness of experimental scaling of river and delta morphodynamics and stratigraphy. Earth-Science Reviews 133: 43-61. http://dx.doi.org/10.1016/ j.earscirev.2014.03.001.

Kraal, E.R., van Dijk, M., Postma, G. \& Kleinhans, M.G., 2008. Martian steppeddelta formation by rapid water release. Nature 451: 973-976 (21 February 2008). http://dx.doi.org/10.1038/nature06615.

Lawson, E.A., 2004. The nature and development of scientific reasoning: a synthetic view. International Journal of Science and Mathematics Education 2: 307-338.

Lawson, E.A., 2009. Basic inferences of scientific reasoning, argumentation, and discovery. Science Education 94: 336-364. doi: 10.1002/sce.20357.

Marra, W.A., Braat, L., Baar, A.W. \& Kleinhans, M.G., 2014. Valley formation by groundwater seepage, pressurized groundwater outbursts and crater-lake 
overflow in flume experiments with implications for Mars. Icarus 232: 97-117. http://dx.doi.org/10.1016/j.icarus.2013.12.026.

Morbidelli, A., Chambers, J., Lunine, J.I., Petit, J.M., Robert, F., Valsecchi, G.B. \& Cyr, K.E., 2000, Source regions and timescales for the delivery of water to the Earth. Meteoritics \& Planetary Science 35: 1309-1320. doi:10.1111/j.1945-5100.2000.tb01518.x.

Paola, C., Straub, K., Mohrig, D. \& Reinhardt, L., 2009. The 'unreasonable effectiveness' of stratigraphic and geomorphic experiments. Earth-Science Reviews 97: 1-43.

PISA, 2006. Science competencies for tomorrow's world, volume 1: Analysis. OECD: 383 pp. http://www.oecd.org/pisa/.

Platt, J.R., 1964. Strong inference. Science 146: 347-353.

Reynolds, 0., 1889. Report of the committee appointed to investigate the action of waves and currents on the beds and foreshores of estuaries by means of working models. British Association Report. Reprinted in: Papers on mechanical and physical subjects, Vol. II, 1881-1900, Cambridge University Press, 1901, Chapter 57, 380-409.

van Dijk, M., Kleinhans, M.G., Postma, G. \& Kraal, E., 2012. Contrasting morphodynamics in alluvial fans and fan deltas: effect of the downstream boundary. Sedimentology 59: 2125-2145. http://dx.doi.org/ 10.1111/j.1365-3091.2012.01337.x. van Keulen, J. \& Sol, Y., 2012. Talent ontwikkelen met wetenschap en techniek. Utrecht University, Centrum voor Onderwijs en Leren, 116 pp. www.wetenschapsknooppunten.nl, last accessed in January 2014.

van Wessel, T., Kleinhans, M.G., Baar, A.W. \& van Keulen, J., 2014. Wetenschapper in de klas: Wetenschappelijk onderzoek en technologie vertalen naar onderzoekend en ontwerpend leren in het basisonderwijs, Utrecht University, Centrum voor Onderwijs en Leren: $70 \mathrm{pp}$. http://www.uu.nl/onderwijs/onderwijsadvies-training/publicaties/boeken.

Verkade, A. \& Kleinhans, M.G., 2014. Expedition Mundus: a very broad range of school children do science in a classroom game. 13th International Public Communication of Science and Technology Conference, 5-8 May 2014, Salvador, Brazil: 13 pp. http://www.pcst-2014.org/pcst_proceedings/ artigos/alex_verkade_m_kleinhans_stt.pdf.

Walma van der Molen, J.H., van Aalderen-Smeets, S.I. \& Asma, L.J.F., 2010. Teaching science and technology at primary school level: Theoretical and practical considerations for primary school teachers' professional training. Proceedings of the IOSTE Symposium on Science and Technology Education, Vol. 14. The XIV IOSTE International Symposium on Sociocultural and Human Values in Science and Technology Education, June 13th to 18th, 2010, Bled, Slovenia, University of Ljubljana (Slovenia). http://ioste.nmmu.ac.za/en/left/Past+IOSTE+Symposia/. 